\begin{tabular}{|l|l|}
\hline & \\
\hline
\end{tabular}

DOSSIÊ: TEORIA SOCIAL E SOCIOLOGIA EXISTENCIAL

\title{
A subjetividade corporificada nos marcos da sociologia existencial
}

\author{
Embodied subjectivity frameworks of an existential sociology \\ Subjetividad encarnada en los marcos de la sociología existencial
}

Lucas Faial Soneghet ${ }^{1}$

orcid.org/0000-0003-2905-3395

lucas_faial@hotmail.com

Recebido em: 29 ago. 2020.

Aprovado em: 22 out. 2020.

Publicado em: 07 maio. 2021.
Resumo: O artigo propõe um conceito de subjetividade corporificada nos marcos de uma sociologia existencial. Partindo da filosofia existencialista-fenomenológica de Maurice Merleau-Ponty, algumas problemáticas relativas ao sujeito e ao corpo no mundo social são apresentadas. Então, essas questões são trabalhadas com referência à teoria sociológica de Erving Goffman e à obra de Michel Foucault. Através da passagem por esses três autores, constrói-se uma noção de subjetividade corporificada, isto é, um conceito de sujeito que leva em consideração o corpo como nexo fundamental das relações sociais. Por fim, exploram-se duas direções de uma possivel sociologia existencial a partir da noção de subjetividade corporificada.

Palavras-chave: Subjetividade. Corpo. Teoria social. Existencialismo.

Resumen: El artículo propone un concepto de subjetividad plasmado en los marcos de una sociología existencial. A partir de la filosofia existencialista-fenomenológica de Maurice Merleau-Ponty, se presentan algunas cuestiones relacionadas con el sujeto y el cuerpo en el mundo social. Entonces, estas preguntas se trabajan con referencia a la teoría sociológica de Erving Goffman y la obra de Michel Foucault. A través del pasaje por estos tres autores se construye una noción de subjetividad encarnada, es decir, un concepto de sujeto que toma en cuenta el cuerpo como nexo fundamental de las relaciones sociales. Finalmente, se exploran dos direcciones de una posible sociología existencial a partir de la noción de subjetividad encarnada.

Palabras clave: Subjetividad. Cuerpo. Teoria social. Existencialismo.

Abstract: The paper proposes a concept of embodied subjectivity in the framework of an existential sociology. Starting from Maurice Merleau-Ponty's existentialist-phenomenological philosophy, I present some questions concerning the subject and the body in the social world. These questions are then discussed with reference to Erving Goffman's sociological theory and the work of Michel Foucault. Through the works of these three authors, a notion of embodied subjectivity is constructed, that is, a concept of subject that takes into consideration the body as a fundamental nexus of social relations. Finally, two directions of a possible existential sociology are explored from the notion of embodied subjectivity.

Keywords: Subjectivity. Body. Social theory. Existentialism.

\section{Introdução}

Quando se fala de uma sociologia existencial ou uma teoria social com inspirações existencialistas, fala-se de um tipo de composição teórica no qual dois procedimentos lógicos podem estar presentes: a aplicação de conceitos sociológicos a questões consideradas existenciais ou o uso de questões existenciais como ponto de partida e fundamento para a
Artigo está licenciado sob forma de uma licença Creative Commons Atribuição 4.0 Internacional. 
formulação de conceitos e hipóteses sociológicas. Portanto, para enquadrar o presente artigo nos limites do que pode vir a ser considerado uma sociologia existencial, é proveitoso, primeiramente, estabelecer algumas questões a partir de uma breve entrada na filosofia existencialista.

Partindo de uma breve apresentação da filosofia de Maurice Merleau-Ponty, um representante da filosofia existencialista fenomenológica, colocarei em evidência as seguintes problemáticas teóricas: a subjetividade e o corpo no mundo; o mundo enquanto ambiente intersubjetivo; as relações complexas advindas da presença de uma subjetividade corporificada em um mundo social intersubjetivo e intercorpóreo. Portanto, parte-se de um sujeito que é um corpo, ou seja, um sujeito-corpo. Esse sujeito-corpo é, ao mesmo tempo, o veículo da experiência do si mesmo, isto é, uma realidade vivida em primeira pessoa, que constitui o pano de fundo da experiência no mundo, e um objeto, seja quando tomado pela sua capacidade reflexiva, ou quando é tomado em sua posição em instituições sociais e relações de saber/poder. Essa dualidade do sujeito-corpo é denominada aqui de "reversibilidade", conceito de Nick Crossley (1996, 115), cunhado com inspiração no existencialismo-fenomenológico de Merleau-Ponty.

O conceito "sujeito-corpo" é desajeitado e não captura o seguinte argumento que quer exprimir: pela nossa existência corporificada em um mundo social, estamos irremediavelmente e a um só tempo lançados em processos de subjetivação e sujeição. Por subjetivação, referimo-nos aos processos pelos quais o sujeito toma-se a si mesmo e constitui-se sempre de maneira mediada em um mundo social intersubjetivo. Por sujeição, indicam-se os processos nos quais o sujeito é objetificado em relações de dominação, subjugação e violência, não obstante, também tornando-se um tipo sujeito. Sendo assim, os processos sociais que incidem no corpo são, em grande medida, processos de se fazer sujeito, ou nas palavras de Turner (2014, 381), a construção da subjetividade envolve um "projeto corporal".

O artigo é estruturado da seguinte forma: primeiro, uma breve apresentação da filosofia exis- tencialista-fenomenológica de Merleau-Ponty, visando estabelecer as problemáticas existenciais a serem retomadas em uma sociologia existencial do sujeito corporificado; posteriormente, tais problemáticas são consideradas em conjunto com as teorias sociais de Erving Goffman e Michel Foucault, visando estabelecer proximidades e distâncias desses autores com a possibilidade de uma sociologia existencial; por fim, coloco algumas considerações sobre a necessidade de uma sociologia existencial atenta ao sujeito corpóreo e suas vicissitudes, adiantando um conceito de subjetividade corporificada.

\section{Merleau-Ponty: o corpo no mundo}

Segundo Maurice Merleau-Ponty, o ser humano é, primariamente, um ser corporal. Partindo de uma crítica às versões realista e idealista da filosofia do sujeito, bem como à dualidade mente/ corpo tornada paradigmática na obra de Descartes, Merleau-Ponty toma o tema da percepção como tema chave. A percepção é, segundo o autor, uma experiência corporificada, uma "maneira original de se relacionar com um objeto" que é primariamente prática (Merleau-Ponty 2012, 113). Rejeitando tanto a ideia de que a percepção é questão de uma representação interna de um mundo externo, quanto a noção de que a mente é uma substância separada do corpo e que, portanto, é possivel olhar para o mundo "de fora" dele, Merleau-Ponty redefine radicalmente o conceito de percepção e, com ele, algumas dualidades clássicas da filosofia do sujeito.

No lugar das dualidades entre corpo-mente ou sujeito-mundo, Merleau-Ponty propõe um sujeito concreto corporal que está desde sempre engajado com o mundo. Colocado de maneira mais precisa, o sujeito-corpo não deve ser tomado como uma substância fechada em si mesma, mas como uma abertura vivida. Isso significa levar em consideração sua interpenetração profunda com o mundo que é, em primeiro lugar, "o que eu vivo" (Merleau-Ponty 2012, 17) e não o que penso. Decorre de seu estar-no-mundo, ou mais ainda, seu ser-no-mundo, a afirmação de que a percepção, esse modo primário de se relacionar 
com o entorno, parte sempre de uma perspectiva particular cheia de conotações práticas e afetivas (Merleau-Ponty 2012, 26). Assim, corpo e mundo estão em relação de constituição mútua: “...meu corpo é um movimento em direção ao mundo, e o mundo é o ponto de apoio do meu corpo." (Merleau-Ponty 2012, 366).

As distinções rejeitadas pelo filósofo francês - entre sujeito e objeto, corpo e mente, "eu" e mundo - são redefinidas como aspectos entrelaçados e reversiveis de uma mesma trama, chamada de "carne" (Merleau-Ponty 1968). A implicação mútua do sujeito-corpo com o mundo significa que existir enquanto corpo não é uma experiência per se, mas antes, a base de toda experiência: "Mas eu não estou na frente do meu corpo, eu estou nele, ou melhor, eu sou ele" (Merleau-Ponty 2012, 151). Isso não significa, porém, que é impossivel experimentar o próprio corpo de maneira análoga a que experimentamos um objeto que percebemos e sentimos. A consciência do próprio ser corporificado como se fosse outra coisa é possivel pelas nossas interações com outros e com o mundo: "...há um mundo para mim porque eu não estou inconsciente de mim mesmo; eu não estou escondido de mim mesmo porque eu tenho um mundo" (Merleau-Ponty 2012, 311). Aí reside a ambiguidade do sujeito-corpo como aquele que vê e que é visto, mas que só é visto porque, primeiramente, vê. Nesse sentido, "o corpo é uma coisa entre coisas", isto é, pertence a "ordem do 'objeto' e a ordem do 'sujeito'" (Merleau-Ponty 1968, 137).

O sujeito-corpo de Merleau-Ponty está no mundo, ou antes, é no mundo em seu engajamento prático com o entorno. Tal engajamento é constituído em uma relação ativa como mundo, de modo que percebê-lo, agir nele e fazer sentido dele são parte da mesma abertura ontológica do ser. Se o ser humano está aberto ao mundo desde sempre em um estado pré-consciente, e se esse mundo também é habitado por outros seres humanos, pode-se falar de um "espaço intermundano" no qual todos os sujeitos-corpos habitam (Merleau-Ponty 1968, 269). Temos então um senso de "intercorporeidade" (Merleau-Ponty 1968, 143) que aponta para um pertencimento que agrupa os sujeitos em um mundo comum. Merleau-Ponty argumenta que mesmo que discordem entre si sobre esse mundo, concebendo-o de maneiras radicalmente diferentes, os sujeitos só o fazem porque partem do mesmo "chão" ontológico, esse pertencimento intercorpóreo ao mundo.

A intercorporeidade é, porém, uma dimensão dessa vivência do sujeito-corpo no mundo com outros sujeitos-corpos. Há outro elemento a ser destacado que é outro mediador importante na relação do sujeito consigo mesmo e com os outros. Enquanto a intercorporeidade já está presente no estado perceptual-prático que é "pré-objetivo" e "pré-consciente", a intersubjetividade constrói-se também pela linguagem. O que há na linguagem e que será crucial para a postulação de um conceito de subjetividade corporal nos moldes de uma sociologia existencial, é seu caráter sócio-histórico institucional, que Merleau-Ponty encontra em Saussure (Merleau-Ponty 1964). Enquanto instituição social, a linguagem nada mais é do que um conjunto de regras e recursos compartilhados. Não obstante, tais regras e recursos não existem como dimensão abstrata que paira sobre a vida dos sujeitos, mas como realidade situada, reproduzida em práticas comunicativas corporais, ou em outras palavras, "por um certo estilo de falar" (Merleau-Ponty 1964, 88).

O caráter sócio-histórico culturalmente específico da linguagem, bem como seu enraizamento nas práticas comunicativas cotidianas se expressam sucintamente na máxima: "Signos organizados tem seu sentido imanente, que não emerge do 'eu penso', mas do 'eu sou capaz de'" (Merleau-Ponty 1864, 88). A fala, diferente da linguagem enquanto instituição sócio-histórica composta de regras e recursos compartilhados, é o momento em que a intenção significativa, o movimento do sujeito-corpo em direção ao fazer sentido do mundo, "se prova capaz de incorporar a si mesma na minha cultura e na cultura dos outros - de me moldar e moldar os outros transformando o sentido dos instrumentos culturais" (Merleau-Ponty 1964, 92). Portanto, na linguagem encontramos não somente o ancoramento do 
sujeito em uma situação sócio-histórica especifica e em um contexto cultural, mas também outra camada de sua existência intersubjetiva, adicionada e intimamente vinculada a sua intercorporeidade:

Na experiência do diálogo, um chão comum é constituido entre eu e outro; meu pensamento e o seu formam um único tecido, minhas palavras e aquelas do meu interlocutor são suscitadas pelo estado da discussão e são inseridas em uma operação compartilhada da qual nenhum de nós dois é o criador. Aqui, há um ser-partilhado-por-dois, e a outra pessoa não é para mim um simples comportamento em meu campo transcendental, nem eu sou, nesse sentido, um simples comportamento no dele. (Merleau-Ponty 2012, 370).

A linguagem na prática, a capacidade reflexiva do sujeito e seu lugar no meio social formam um entrelaçado de dimensões mutuamente constituidas, uma trama, semelhante e implicada naquele nexo de reversibilidades que Merleau-Ponty denominou carne. A carne do corpo e a carne do mundo (Merleau-Ponty 1968) se encontram no locus que é o sujeito-corpo.

A princípio, o ato de perceber não implica em consciência de si enquanto aquele que percebe ou mesmo pensamento reflexivo: "Mas vimos que a percepção primária é uma experiência não-tética, pré-objetiva e pré-consciente" (Merleau-Ponty 2012, 252). Ao nos encontramos no mundo como seres corporais, já estamos ontologicamente abertos a ele, ou seja, o estado perceptivo do sujeito-corpo em relação aos objetos no mundo independe de elaborações reflexivas ou "conteúdos de consciência", na terminologia de Husserl. Trata-se, antes, de um estado primário pré-reflexivo no qual o sentido ou o senso é conteúdo de uma experiência caracterizada pelo "ajuste" intuitivo entre sujeito e mundo:

A coisa é inseparável de uma pessoa percebendo-a e nunca pode ser realmente em si mesma porque suas articulações são aquelas da nossa própria experiência, e porque está na outra ponta de nosso olhar ou no terminus de uma exploração sensorial que a investe de humanidade. Nesta medida, cada percepção é uma comunicação ou uma comunhão, a tomada ou conclusão por nós de alguma intenção alheia ou, por outro lado, a expressão completa fora de nós mesmos dos nossos poderes perceptivos e uma coisificação, por assim dizer, do nosso corpo com as coisas. (Merleau-Ponty 2012, 334).

As coisas e os outros sujeitos "fazem sentido" perceptualmente antes mesmo de haver qualquer elaboração discursiva sobre elas. Merleau-Ponty toma a noção de "intencionalidade" de Husserle a desloca, afastando-a da ideia de uma representação mental e aproximando-a da ideia de uma responsividade do corpo em seu engajamento com o mundo e as coisas. Esse sentido imediato corporal é a base do sentido reflexivo alcançado pelo intelecto e posteriormente objetivado na linguagem, sendo essa o único meio pelo qual seres humanos podem se tornar conscientes de seu próprio pensamento.

Ao localizar o corpo prático no mundo e definir o mundo como espaço intercorpóreo e intersubjetivo, Merleau-Ponty gera a imagem de um ser humano marcado por uma série de reversibilidades constitutivas. Tais reversibilidades incluem: sensivel e senciente, visto e vedor, passivo e ativo, construido e construtor, significado e significante. No entanto, suas competências reversíveis só ganham movimento, só se realizam em sua reversibilidade dinâmica quando consideramo-lo em sociedade:

Então, devemos redescobrir o mundo social, depois do mundo natura, não como objeto ou soma de objetos, mas como o campo permanente ou dimensão da existência: eu posso certamente virar as costas para o mundo social, mas não posso deixar de estar situado em relação a ele. Nossa relação com o social, assim como nossa relação com o mundo, é mais profunda do que qualquer percepção explícita e mais profunda do que qualquer julgamento. (Merleau-Ponty 2012, 379).

Temos então, partindo de Merleau-Ponty, algumas problemáticas para uma sociologia existencial do sujeito corpóreo. Primeiro, o filósofo francês aponta para as falhas de um possivel raciocínio dicotômico que separe o sujeito de seu entorno, seja esse o mundo natural ou o mundo social. Segundo, o sujeito corpóreo não é uma entidade com qualidades dadas de antemão, mas um ser em processo de constituição a partir de suas relações com o entorno. A máxima 
existencialista da precedência da existência em relação à essência, encontrada em Sartre (2007), bem como a postulação de uma existência incorporada maleável em Merleau-Ponty, abrem espaço para discutir as minúcias do processo de se tornar um sujeito. Por fim, os modos de relação entre o sujeito corpóreo, o mundo e os outros, são, pelo menos em alguma medida, sócio-historicamente e culturalmente especificos. Diante dessas problemáticas, voltamo-nos agora para a teoria interacionista de Erving Goffman, visando discutir as noções de um self incorporado e de uma dinâmica intercorporificada da vida social.

\section{Goffman: o self incorporado nos jogos de interação}

Erving Goffman interessou-se por dois grandes temas da teoria sociológica: a dinâmica da interação social e a manutenção da ordem social pelas ações dos individuos em interação. Há em Goffman um paralelo com outro filósofo existencialista que, de certa forma, preenche uma lacuna sociológica deixada na concepção de sujeito corporificado em Merleau-Ponty. No coração da ontologia existencialista de Jean-Paul Sartre (2007) está o nada ou a indeterminação da existência humana que se traduz no conceito de liberdade. Existimos enquanto seres inelutavelmente livres, portanto, temos a responsabilidade de escolher como viver, de definir a nós mesmos e nossas ações. Não obstante, sujeito livre não necessariamente corresponde a sua responsabilidade e pode viver em "má-fé". Viver em má fé significa negar a responsabilidade advinda da liberdade radical da qual todo ser humano está imbuido. Em última instância, apesar de todas as pressões externas, Sartre argumenta que todos somos livres para decidir se nos conformamos ou não com os papeis impostos a nós. Adotar uma atitude de má-fé seria enganar a si mesmo afirmando que o seu comportamento foi totalmente determinado por fatores externos.

Podemos firmar um paralelo entre a má-fé e a distância performativa entre o indivíduo e o papel que representa, enfatizada por Goffman (1961) em seu estudo sobre a vida de individuos em "instituições totais". Mesmo em situações em que aparentemente parecem estar totalmente determinados pelos papeis impostos a eles, como em uma prisão ou manicômio, há para os indivíduos algum espaço de manobra que está "além do alcance da organização" (Goffman 1961, 276). Não obstante, o conceito de má-fé em Sartre está implicado em noções normativas de autenticidade e liberdade, enquanto para Goffman, a distância entre a identidade social imposta e o indivíduo é fato comum, sem qualquer denotação positiva ou negativa a priori. A vida social é, por isso, o processo de manter o equilibrio entre identidade social, self incorporado e situações de interações.

Esse delicado equilibrio torna-se evidente quando olhamos para as manifestações corporais que o prejudicam: "Em nossa sociedade, alguns gestos não intentados ocorrem em uma variedade tão ampla de performances e dão impressões que são, em geral, tão incompativeis com aquelas que estão sendo sustentadas, que esses eventos inoportunos adquiriram status simbólico coletivo" (Goffman 1956, 34). Tropeços, quedas, bocejos e arrotos são eventos corporais que lançam luz na necessidade da manutenção de um "cuidado expressivo", calcado no autocontrole do indivíduo sobre seu corpo. Ao falhar em agir de modo que seja percebido pelos outros de maneira apropriada em determinada situação e de acordo com determinada identidade, o self incorporado não coloca em risco somente a si mesmo, mas também a todos os que com ele estão envolvidos em interação. O objetivo implícito do manejo corporal apropriado é, portanto, a manutenção da ordem da interação que resulta das práticas do self incorporado em relação com os outros. Goffman (1983, 3) afirma então que "...na ordem de interação, o absorvimento e envolvimento dos participantes - ou ao menos de sua atenção - é crucial...", o que introduz um "elemento psicobiológico inevitável" no processo de manutenção da ordem social.

As competências finas necessárias a manutenção ordeira da interação não são, todavia, inerentes ao ser humano. Há um processo de socialização do corpo, ou seja, de padronização de comporta- 
mentos vocais e corporais através da socialização que permite que estes tenham uma função comunicativa especifica e compreensivel (Goffman 1983, 3). O self performativo conceituado por Goffman aprende a agir, a ler outros corpos e a tornar-se legivel no mesmo processo, ao longo do qual incorpora vocabulários compartilhados de "idiomas corporais". Um idioma corporal funciona como um "discurso convencionalizado" (Goffman 1963, 35) que é normativo e necessário, ou seja, obriga o sujeito a se comportar de certa forma a todo o momento.

Semelhante a Merleau-Ponty, Goffman oferece uma descrição do corpo como força ativa no mundo, tanto na performance de suas competências quanto no seu engajamento perceptual com as situações nas quais se encontra. No livro Relations in public (1971), dedicado ao estudo da ordem de interações em espaços públicos, Goffman (1971, 11) usa o conceito de "scanning" para se referir a checagem contínua do ambiente e dos outros, indicando uma postura ativa de posicionamento corporal concomitante a uma sensibilidade perceptiva ao entorno. As percepções do ambiente estão associadas, porém, a um conjunto de regras particulares de interação relativas à situação social concreta. Dito de outro modo, na investigação das relações em público, Goffman aponta para os cenários nos quais as práticas sociais se desenrolam (nesse caso especifico, a rua) e as regras e padrões de comportamento desses cenários. Encontramos em Goffman uma noção de intersubjetividade e intercorporeidade que podem ser postas em paralelo àquelas de Merleau-Ponty.

Em Forms of talk (Goffman 1981), a análise das interações face a face é feita em termos das conversas. Aqui, o autor está interessado nos rituais, enquadramentos e "movimentos" dos atores enquanto falam uns com os outros. A noção de "situação social" mobilizada é particularmente interessante para os propósitos desse argumento: "...o total da arena física na qual as pessoas presentes estão ao alcance da vista e dos ouvidos uns dos outros." (Goffman 1981, 136, tradução própria). O termo "física" não é fortuito, pois no terceiro ensaio do livro, Goffman aborda a fala como um conjunto de posição corporal e entona- ção, afetados pela mudança do "enquadramento de participação" no qual os atores se encontram. O enquadramento de participação é o conjunto de relações de cada membro de uma situação em relação a um enunciado. Logo, é um "leque de possibilidades estruturalmente diferenciadas" dentro do qual os atores podem agir de acordo com o que está sendo dito (Goffman 1981, 137). Por exemplo, quando um professor conta uma piada considerada imprópria em sala de aula, os alunos se encontram, de acordo com seu status e posição naquele enquadramento de participação, diante de um conjunto de possiveis reações: rir forçadamente, ficar em silêncio como forma de demonstrar desaprovação ou mesmo apontar a natureza inadequada da fala do professor. Cada possibilidade envolve não somente um ato verbal de fala, mas também mudanças sutis em postura corporal e expressão facial.

Considerando o corpo em interação, temos uma condição corporal que é dual e reversivel: o corpo é instrumento na ação e percepção, bem como superficie para a ação e percepção de outrem. Com essa condição dual e reversivel, Goffman desenvolve uma teoria do self incorporado, na qual corpo é o mediador entre a identidade de si (self-identity) - o senso subjetivo que o sujeito tem de sua própria situação e da continuidade e caráter que adquire como resultado de suas experiências (Goffman 1968, 129) - e a identidade social - atributos assinalados a um grupo de indivíduos considerados semelhantes. Na realização do trabalho de mediar o senso subjetivo de si, aquilo que o sujeito considera ser "o que ele realmente é", e os traços atribuidos a ele de acordo com sua posição social, o corpo é um "equipamento importante" (Goffman 1967, 167), mas também uma superficie, isto é, um plano visivel suscetível a avaliações, julgamentos, normas e valores. Tal aspecto reversivel do corpo, bem como seu papel de mediador entre senso subjetivo de si e identidade social são colocados de maneira explícita no estudo sobre as relações em público:

Deixe-me repetir: o self é o código que dá sentido a quase todas as atividades do individuo e fornece uma base para organizá-las. Esse 
self é o que pode ser lido sobre o indivíduo interpretando o lugar que ele toma em uma organização de atividades sociais, como confirmado pelo seu comportamento expressivo. 0 fracasso do individuo em codificar, através de atos e sugestões expressivas, uma definição viável de si mesmo, uma que os seus próximos possam atribuir a ele de acordo com a estima que demonstram por sua pessoa, resulta em bloqueá-los, atrapalhá-los e ameaçá-los em quase todo movimento que fizerem. Os selves que foram os reciprocos do seu são minados. (Goffman 1971, 366, tradução própria).

Temos assim o self incorporado como elemento chave na ordem de interação e o processo de socialização do corpo em idiomas corporais compartilhados, portanto, resta aprofundar a questão de seu papel mediador. No estudo do estigma e das "identidades deterioradas", Goffman lança luz sobre àqueles membros da sociedade que, em decorrência de certos atributos considerados negativos, experimentam uma discrepância entre sua identidade social virtual - conjunto de expectativas potencialmente aplicáveis ao individuo de acordo com sua possivel identidade social - e identidade social atual - a instanciação concreta dessas expectativas quando se averigua que o indivíduo de fato pertence a tal ou qual identidade social. Shilling (1993) argumenta que a análise do estigma pode ser lida como um tratado sobre as várias formas pelas quais o corpo e as normas em torno dele mediam a relação entre identidade social e identidade de si. Isso porque, com o manejo do corpo, o self performativo pode manipular o grau de visibilidade de certos traços que poderiam, caso percebidos, associá-lo a uma identidade social deteriorada. Para além dos casos de estigma, o corpo continua sendo um fulcro entre o senso de si e a identidade social, como por exemplo, na discussão sobre comportamentos que denotam status de classe:

Esses comportamentos envolvem questões de etiqueta, vestimenta, postura, gesticulação, entonação, dialeto, vocabulário, movimentos corporais pequenos e avaliações expressadas de maneira automática acerca da substância e dos detalhes da vida. De certo modo, esses comportamentos constituem um estilo social. (Goffman 1951, 300).
Nota-se que Goffman abre espaço para um conceito de subjetividade que é modelada socialmente até em sua realidade corporificada, isto é, um sujeito corporificado que é não somente princípio ativo da vida social, mas também locus no qual relações de poder e desigualdades estruturais atuam e se concretizam. Aqui, encontra-se um caminho para um aspecto frequentemente posto em segundo plano, mas não totalmente ignorado, pela filosofia existencialista: a constituição social do sujeito pelo seu corpo em relações de poder.

\section{Foucault: o sujeito entre saberes, poderes e técnicas de si}

Podemos entender o lugar da subjetividade na obra de Michel Foucault em termos de uma tripla objeção a hipóteses correntes sobre o saber, o poder e o sujeito nas ciências humanas e sociais de sua época: objeção a uma "filosofia do sentido" que não incluísse "os mecanismos formadores de significação e a estrutura dos sistemas de sentido" na explicação do sentido, voltando-se ou para uma explicação estruturalista fundada na articulação de símbolos em um esquema de diferenças à moda de Saussure ou para uma explicação reducionista que explicaria o sentido em termos de relações de produção à moda de Marx (Foucault 2006, 94); a uma filosofia do poder que o conceituasse como um "sistema geral de dominação exercida por um elemento ou grupo sobre outro", que pressupusesse o estado soberano ou a lei, definindo-o então como "a multiplicidade de correlações de força imanentes ao domínio onde se exercem e constitutivas de sua organização" (Foucault 1988, 88); a uma "filosofia do sujeito" ou a uma "filosofia da consciência" herdeira de Husserl, que postulava uma teoria "anterior e universal do sujeito" correlata "a uma experiência original e fundadora" do que é ser sujeito (Foucault 2017, 12, tradução própria).

Foucault via Merleau-Ponty como participante da tradição de uma filosofia "do sentido, do sujeito" (Foucault 2000, 353). O sujeito-corpo de Merleau-Ponty, principio e veículo da experiência incorporada do mundo, é reconsiderado na obra de Foucault à luz de uma "arqueologia", uma 
"genealogia" e uma "história do sujeito", cada qual correspondente a uma das três objeções elencadas anteriormente.

A arqueologia é o método principal em obras como A Arqueologia do saber (1987) e História da loucura na Idade Clássica (1999a), nas quais Foucault estuda o sujeito do ponto de vista de uma teoria do sentido que tomasse as ciências humanas como "saberes que permitem conhecer os que os indivíduos são" (Foucault 2006, 54). As ciências humanas dos séculos 17 e 18 são tomadas então como "filosofias do sujeito como ser que fala, vive e trabalha" (Foucault 2006, 94). O sujeito é o objeto formado nos sistemas de ordenamento do discurso que visam controlar, selecionar, organizar e redistribuir os enunciados acerca desse objeto.

Na genealogia do sujeito, está em jogo tanto a objeção a uma teoria do poder como sistema geral unitário no qual o rei, a lei ou o estado seriam centro e principio de organização, quanto a uma teoria do poder que o reduzisse às relações materiais de produção. Assim, a questão é entender as grandes "máquinas disciplinares" ou instituições dedicadas a "apreender o individuo, saber o que ele é, o que ele faz, o que se pode fazer dele, ou onde é preciso colocá-lo, como situá-lo entre os outros" (Foucault 2006, 54). O estudo das instituições e práticas de controle visa "mostrar como são as relações de sujeição efetivas que fabricam sujeitos" (Foucault 1999b, 51). Mais uma vez, o sujeito, assim como o corpo, são produtos de outras realidades, sendo enfatizados os processos de sujeição, isto é, os processos por meio dos quais técnicas de poder e de produção de saber localizadas em instituições - o hospital e a medicina anatomopatológica, bem como a prisão e a criminologia, são alguns exemplos de articulações históricas do poder-saber - "aplicadas aos corpos haviam feito sair desses corpos sujeitados algo que era uma alma-sujeito, um 'eu', uma psique, etc". (Foucault 1999b, 221) O corpo é o locus de produção da subjetividade e esta é resultado dos processos de sujeição levados adiante por instituições que cristalizam certas articulações entre poder e saber.
Por fim, começando com o primeiro volume da obra A História da sexualidade (1988) e seguindo pelos cursos ministrados no Collège de France ao longo de meados da década de 1970 e pela década de 1980 até sua morte. Foucault recolocou sua obra em termos da problemática da subjetividade e dos jogos de verdade:

Após o estudo dos jogos de verdade considera-
dos entre si - a partir do exemplo de um certo
número de ciências empiricas nos séculos 17 e
18 - e posteriormente ao estudo dos jogos de
verdade em referência às relações de poder, a
partir do exemplo das práticas punitivas, outro
trabalho parecia se impor: estudar os jogos de
verdade na relação de si para si e a constituição
de si mesmo como sujeito. (Foucault 1984, 11).

Nesse último momento da obra de Foucault, acreditamos ser possivel encontrar uma consolidação da problemática da subjetividade. Isso não significa tomar toda a obra à luz dos escritos desse periodo, mas escolher um ponto no qual as questões importantes para esse artigo, a saber, do sujeito e do corpo em uma sociologia existencial, encontram uma formulação apropriada para a argumentação aqui desenvolvida. No estudo das "práticas de si", esses modos pelos quais os sujeitos são levados a tomarem a si mesmos enquanto sujeitos, a se decodificarem, manejarem, treinarem e controlarem, aparece um outro lado do processo de sujeição, já tão evidente nas instituições de controle estudadas no marco da genealogia:

Parece-me que nesta análise das tecnologias de si [...] podemos ainda assim apreender um momento historicamente importante nesta história que seria a história da subjetividade - da subjetividade entendida como o conjunto de processos de subjetivação a que os individuos foram submetidos ou que implementaram em relação a si próprios. (Foucault 2017, 282, tradução própria).

Entre sujeição e subjetivação, está a subjetividade. É preciso ressaltar, ainda, a importância do corpo na história da subjetividade foucaultiana, pois tanto do ponto de vista do poder, quanto dos saberes, o corpo é a "superfície" por excelência (Foucault 1977, 175). A diferença entre sujeição 
e subjetivação não é análoga a uma diferença entre um sujeito fabricado pelo poder e por ele sujeitado de um lado, e um sujeito que se faz por si mesmo do outro. Toda subjetividade, para Foucault, é uma realidade sócio-histórica atravessada por relações de poder e jogos de verdade. Ao ser perguntado sobre o que é o sujeito, Foucault responde:

Não é uma substância. É uma forma, e essa forma nem sempre é, sobretudo, idêntica a si mesma. Você não tem consigo próprio o mesmo tipo de relações quando você se constitui como sujeito político que vai votar ou tomar a palavra em uma assembleia, ou quando você buscar realizar o seu desejo em uma relação sexual. Há, indubitavelmente, relações e interferências entre essas diferentes formas do sujeito: porém, não estamos na presença do mesmo tipo de sujeito. Em cada caso, se exercem, se estabelecem consigo mesmo formas de relações diferentes. E o que me interessa é, precisamente, a constituição histórica dessas diferentes formas do sujeito, em relação aos jogos de verdade. (Foucault 2006, 275).

Se o sujeito é uma forma, isto é, um conjunto de traços variáveis historicamente que não possui essência ou substância especifica e universal, o que se pode dizer sobre o duplo processo de sujeição e subjetivação? O sujeito e seu corpo são objetos fabricados pelo discurso das ciências humanas e efeitos das relações de poder institucionalizadas? Ou é possivel falar de algum sujeito que age, que reage e que age sobre si? A máxima foucaultiana de que "onde há poder, há resistência" (Foucault 1988, 91) não nos leva muito adiante em termos de uma teoria da subjetividade corporificada, pois não diz nada sobre o funcionamento e a forma dessa resistência. O conceito de subjetivação não ganha formulação definitiva em sua obra, às vezes sendo equacionado com uma "relação com uma verdade reconhecida, [...] adquirida pela produção de uma verdade interior, secreta, oculta" (Foucault 2008, 243) e às vezes sendo usado como termo que engloba a sujeição (Foucault 1984, 27-29). Ao fim e ao cabo, a distinção entre subjetivação e sujeição parece ser muito frágil, pois, o que de fato se conclui da "filosofia do sujeito" de Foucault é que toda relação do sujeito consigo mesmo é mediada por instâncias sociais. Tais instâncias podem ser saberes, tecnologias, instituições, relações com outros individuos e técnicas corporais variadas. Não obstante, é possivel diferenciar analiticamente a sujeição da subjetivação da seguinte forma: na sujeição, como ocorre na captura do sujeito por instituições de controle como a prisão, o sujeito tende a ser tomado enquanto objeto, isto é, enquanto ente com propriedades fixas relativas aos fins da instituição especifica na qual se encontra apreendido; na subjetivação, o sujeito toma a si mesmo, sempre de maneira mediada, enquanto um sujeito, isto é, enquanto ente com propriedades modeláveis e capaz de transformar a si mesmo. A distinção ainda é demasiado tênue, mas, por agora, serve para avançar o argumento.

O que devemos salientar é a conceituação do sujeito como uma obra resultante de práticas, sejam elas práticas de significação, de dominação ou de si. As primeiras dizem respeito a "utilizar sistemas de signos", as segundas tratam de "determinar a conduta dos indivíduos, impor certas finalidades ou determinados objetivos", e as últimas "permitem aos indivíduos realizar, por eles mesmos, um certo número de operações em seu corpo, em sua alma, em seus pensamentos, em suas condutas" (Foucault 2006, 95), de modo que o problema da subjetividade corporificada é o problema do entrecruzamento entre essas práticas em um determinado momento histórico. Não há uma concepção universal basilar de sujeito, mas há algum principio de "autoconduta", uma vez que se reconhece que, mesmo que por meio de técnicas impostas e, portanto, impregnadas de assimetrias de poder, o sujeito é capaz de relacionar-se consigo mesmo e, nessa relação, praticar sua liberdade. O sujeito não é, portanto, aquele caracterizado por uma liberdade que é estrutura ontológica de todo ser humano, e suas relações com o mundo e consigo não podem ser entendidas no marco de uma filosofia da percepção enquanto faculdade humana universal. É preciso atentar para as "práticas de liberdade", as formas de se exercer a si mesmo diante de um "campo extremamente complexo" de relações de poder. Praticar a liberdade não é, todavia, agir 
em um meio onde não há mais poder, mas sim encontrar meios de "se conduzir eticamente" nas relações com os outros em "um campo para novas relações de poder, que devem ser controladas por práticas de liberdade" (Foucault 2006, 267).

\section{O sujeito e suas reversibilidades}

Começando em Merleau-Ponty e passando por Goffman e Foucault, tem-se um conjunto de características do que chamarei de uma existência corporificada-subjetiva. Tal existência é tomada como fundamento da vida em sociedade devido a três argumentos desenvolvidos ao longo do artigo: a abertura ontológica do corpo; a dimensão intersubjetiva e intercorporificada da vida em sociedade; o papel mediador do corpo no posicionamento do sujeito em relações, situações e instituições sociais. No entanto, postular que a vida em sociedade se constrói a partir de algumas faculdades corporificadas é somente o primeiro passo. Qual a natureza das relações que se constituem no corpo e pelo corpo na sociedade? Ou ainda, como a sociedade é constituida pelas práticas incorporadas interrelacionadas de sujeitos? Tais questões estão para além do escopo desse texto, no entanto, acredito que seja possivel ensaiar duas direções para uma sociologia existencial da subjetividade corporificada a partir do que foi argumentado até aqui.

Primeiro, se deve partir de uma noção de corpo estanque, com faculdades pressupostas e com traços definitivos. Se há algo que a ética do cuidado e os disability studies (Kittay 1999; Von der Weid 2018) nos ensinam é que a corporalidade é traço crucial da vida social, porém não se deve concebê-la em termos normativos e excludentes. Em outras palavras, o corpo como elemento fundamental para a vida em sociedade não deve ser definido por certos sentidos, a visão, por exemplo, ou certas capacidades, como o movimento sem auxilio de instrumentos. Trata-se de definir, por outro lado, o corpo pela sua abertura ontológica ou, dito de outra forma, pela sua vulnerabilidade. O conceito de vulnerabilidade indica a possibilidade de que o corpo seja "agido sobre" das mais variadas formas. Vio- lência, carinho, abandono e amor são formas de relação entre corpos que só são possiveis pelas suas vulnerabilidades mutuamente implicadas. Não obstante, a vulnerabilidade pode ser "exacerbada" em condições socioeconômicas e em relações de poder especificas (Butler 2004, 29). Sendo assim, ser vulnerável é ser potencialmente suscetivel a realidades existenciais como a morte e a angústia (Turner 2014, 383) e sujeitado a certas realidades socialmente constituídas de violência, esquecimento e destruição (Butler 2004). A especificidade da vulnerabilidade humana, portanto, está no fato de que além de estar suscetivel a dor, a doença e a morte, como os outros animais, estamos suscetiveis a práticas sociais especíicas como a linguagem (Das 2015, 129).

Não se deve assumir, portanto, que uma dimensão da vulnerabilidade, qual seja aquela mais ontológica e basilar associada a inevitabilidade da morte por exemplo, tem prioridade e determina a outra, aquela vinculada a condições sociais de exacerbação da fragilidade corporal. A relação não é de determinação e nem possui somente um sentido, pois a vulnerabilidade corporificada institui tanto a possibilidade de relações negativas como a violência e o abandono quanto a possibilidade de relações positivas como o carinho e a compaixão. O objetivo da sociologia existencial da subjetividade corporificada é, então, investigar os processos de modulação social da vulnerabilidade que, por partirem da condição corporificada, a modificam e a reconstroem

Em segundo lugar, a investigação dos processos de modulação social da vulnerabilidade e, portanto, da subjetividade corporificada, não ocorrem somente no âmbito das grandes instituições de poder estudadas por Foucault, nem no plano das microinterações analisadas por Goffman. Antes ainda, a distinção entre um nivel de análise e outro, bem como as distinções entre material e simbólico, agência e estrutura, sujeito e objeto, humano e não humano, devem ser reconsideradas a luz da subjetividade corporificada como um nexo de reversibilidades em relações reversiveis com o mundo. O termo "reversibilidades" indica as supostas dualidades da existência 
corporal subjetiva: objetividade-subjetividade, passividade-atividade, maleabilidade-durabilidade. Essas "dualidades fenomenológicas" da subjetividade corporificada devem ser consideradas como dimensões da experiência cujas relações são mediadas por práticas (Morgan 2002, 87). Não há motivo para definir de antemão se tais práticas são "discursivas", "simbólicas", "interacionais", "materiais", "conscientes" ou "inconscientes". O que se deve ressaltar é que ser um sujeito e ser um corpo é um trabalho contínuo que se desenvolve em relações com outros entes no mundo. Neste trabalho, não é só o sujeito e seu corpo que se reconstroem, mas também o mundo, os outros e as relações entre estes. Por isso, falo de relações reversíveis, uma vez que mesmo em "estados de dominação" nos quais as relações estão "bloqueadas e cristalizadas" e, portanto, resistem à mudança (Foucault 2006 , 266), permanece a possibilidade desestabilização e reversão. Tal possibilidade se funda na reversibilidade da subjetividade corporificada que, mesmo quando no terreno das subjetividades dispersas e precarizadas que caracterizam o mundo contemporâneo (Das 2015, 28), ainda existe o potencial de praticar a liberdade.

\section{Referências}

Butler, Judith. 2004. Precarious life: the powers of mourning and violence. Nova lorque: Verso Books.

Crossley, Nick. 1996. Body-subject/body-power: agency, inscription and control in Foucault and Merleau-Ponty. Body \& Society 2 (2): 99-116. https://doi. org/10.1177/1357034X96002002006.

Das, Veena. 2015. Affliction: health, disease, poverty. Nova lorque: Fordham University Press.

Foucault, Michel. 1977. O nascimento da clínica. Rio de Janeiro: Forense Universitária.

Foucault, Michel. 1984. História da sexualidade. O uso dos prazeres, vol. 2. Rio de Janeiro: Edições Graal.

Foucault, Michel. 1987. A arqueologia do saber. Rio de Janeiro: Forense Universitária.

Foucault, Michel. 1988. História da sexualidade. A vontade de saber, vol. 1. Rio de Janeiro: Edições Graal.

Foucault. Michel. 1999a. História da loucura na idade clássica. São Paulo: Editora Perspectiva.
Foucault, Michel. 1999b. Em defesa da sociedade: curso no Collège de France (1975-1976). São Paulo: Martins Fontes.

Foucault, Michel. 2000. Ditos e escritos: arqueologia das ciências e história dos sistemas de pensamento, vol. 2. Rio de Janeiro: Forense Universitária.

Foucault, Michel. 2006. Ditos e escritos: ética, sexualidade e politica, vol. 5. Rio de Janeiro: Forense Universitária.

Foucault, Michel. 2008. Segurança, território, população: curso dado no Collège de France (1977-1978). São Paulo: Martins Fontes.

Foucault, Michel. 2017. Subjectivity and truth: lectures at the College de France (1980-1981). Reino Unido: Palgrave Macmillan.

Goffman, Erving. 1951. Symbols of class status. British Journal of Sociology 2 (4): 294-304. https://doi. org/10.2307/588083.

Goffman, Erving. 1956. The presentation of self in everyday life. Edimburgo: University of Edinburgh Social Sciences Research Centre.

Goffman, Erving. 1961. Asylums: essays on the social situation of mental patients and other inmates. Nova Iorque: Anchor Books.

Goffman, Erving. 1963. Behaviour in public places. Londres: Allen Lane.

Goffman, Erving. 1967. Interaction Ritual: essays on face-to-face behavior. Nova lorque: Anchor Books.

Goffman, Erving. 1968. Stigma: notes on the management of spoiled identity. Harmondsworth: Penguin Books.

Goffman, Erving. 1971. Relations in public: microstudies of the public order. Nova lorque: Basic Books.

Goffman, Erving. 1981. Forms of talk. Filadélfia: University of Pennsylvania Press.

Goffman, Erving. 1983. The Interaction Order. American Sociological Review 48 (1): 1-17. https://doi. org/10.2307/2095141.

Kittay, Eva Federer. 1999. Love's labor: essays on women, equality and dependence. Nova lorque: Routledge.

Merleau-Ponty, Maurice. 1964. Signs. Chicago: Northwestern University Press.

Merleau-Ponty, Maurice. 1968. The visible and the invisible: followed by working notes. Chicago: Northwestern University Press

Merleau-Ponty, Maurice. 2012. Phenomenology of perception. Nova lorque: Routledge.

Morgan, David. 2002. The body in pain. In Real bodies: a sociological introduction, organizado por Mary Evans e Ellie Lee, 79-96. Nova Iorque: Palgrave Macmillan.

Sartre, Jean-Paul. 2007. O ser e o nada. Petrópolis: Editora Vozes

Shilling, Chris. 1993. The body in social theory. Londres: Sage. 
Turner, Bryan. 2014. Corpo e sociedade. São Paulo: Ideias e Letras.

Von der Weid, Olivia. 2018. Entre o cuidado e a autonomia: deficiência visual e relações de ajuda. Revista Anthropológicas 29 (2): 49-82.

\section{Lucas Faial Soneghet}

Doutorando do Programa de Pós-Graduação em Sociologia e Antropologia (PPGSA), Universidade Federal do Rio de Janeiro (UFRJ), Rio de Janeiro, RJ, Brasil. 